\title{
Seasonal Change in Wetland Coherence as an Aid to Wetland Monitoring
}

\author{
Brian Brisco ${ }^{1}$, Frank Ahern ${ }^{2, *}$, Kevin Murnaghan ${ }^{1}$, Lori White ${ }^{3}$, Francis Canisus ${ }^{1}$ \\ and Philip Lancaster ${ }^{4}$ \\ 1 Canada Centre for Mapping and Earth Observation, 560 Rochester St., Ottawa, ON K1A 0E4, Canada; \\ brian.brisco@canada.ca (B.B.); kevin.murnaghan@canada.ca (K.M.); franciscanisius@yahoo.com (F.C.) \\ 2 TerreVista Earth Imaging, 441 Cormac Road, Cormac, ON K0J 1M0, Canada \\ 3 Environment Canada, 1125 Colonel by Drive, Ottawa, ON K1A 0H3, Canada; lori.white@ec.gc.ca \\ 4 Lancaster Geographics, 187 Mulberry Lane, Lake Clear, RR 2, Eganville, ON K0J 1T0, Canada; \\ philips.lancaster@gmail.com \\ * Correspondence: frank.ahern@xplornet.com; Tel.: +1-613-754-2822
}

Academic Editors: Qiusheng Wu, Charles Lane, Melanie Vanderhoof, Chunqiao Song, Deepak R. Mishra and Prasad S. Thenkabail

Received: 29 November 2016; Accepted: 9 February 2017; Published: 15 February 2017

\begin{abstract}
Water is an essential natural resource, and information about surface water conditions can support a wide variety of applications, including urban planning, agronomy, hydrology, electrical power generation, disaster relief, ecology and preservation of natural areas. Synthetic Aperture Radar (SAR) is recognized as an important source of data for monitoring surface water, especially under inclement weather conditions, and is used operationally for flood mapping applications. The canopy penetration capability of the microwaves also allows for mapping of flooded vegetation as a result of enhanced backscatter from what is generally believed to be a double-bounce scattering mechanism between the water and emergent vegetation. Recent investigations have shown that, under certain conditions, the SAR response signal from flooded vegetation may remain coherent during repeat satellite over-passes, which can be exploited for interferometric SAR (InSAR) measurements to estimate changes in water levels and water topography. InSAR results also suggest that coherence change detection (CCD) might be applied to wetland monitoring applications. This study examines wetland vegetation characteristics that lead to coherence in RADARSAT-2 InSAR data of an area in eastern Canada with many small wetlands, and determines the annual variation in the coherence of these wetlands using multi-temporal radar data. The results for a three-year period demonstrate that most swamps and marshes maintain coherence throughout the ice-/snow-free time period for the 24-day repeat cycle of RADARSAT-2. However, open water areas without emergent aquatic vegetation generally do not have suitable coherence for CCD or InSAR water level estimation. We have found that wetlands with tree cover exhibit the highest coherence and the least variance; wetlands with herbaceous cover exhibit high coherence, but also high variability of coherence; and wetlands with shrub cover exhibit high coherence, but variability intermediate between treed and herbaceous wetlands. From this knowledge, we have developed a novel image product that combines information about the magnitude of coherence and its variability with radar brightness (backscatter intensity). This product clearly displays the multitude of small wetlands over a wide area. With an interpretation key we have also developed, it is possible to distinguish different wetland types and assess year-to-year changes. In the next few years, satellite SAR systems, such as the European Sentinel and the Canadian RADARSAT Constellation Mission (RCM), will provide rapid revisit capabilities and standard data collection modes, enhancing the operational application of SAR data for assessing wetland conditions and monitoring water levels using InSAR techniques.
\end{abstract}

Keywords: SAR; InSAR; coherence; hydrology; flooded vegetation; change detection 


\section{Introduction}

There is an increasing need for improved management of freshwater resources as these resources are becoming increasingly strained and more valuable. The causes are many: increasing populations, increasing agricultural irrigation that often results in over-use or salinization, human populations moving to sunny dry climates with limited water supplies, pollution by agriculture and industry, industrial consumption and climate change. More specifically, wetlands are the most vulnerable landscape feature subject to climate change [1].

Even Canada, a country with abundant water in most places, is experiencing water issues. In the prairies, drought years strain water resources for cities (e.g., Regina) and rural areas (southern Alberta and Saskatchewan). In other areas, industrial use of water is stressing resources. A notable example is the tar sands oil extraction, which requires large quantities of water from the Athabasca River. In addition, ample quantities of water are needed for healthy wetlands, and these wetlands are critical for helping to even out water flows and maintain water quality.

Monitoring surface water can provide critical information for water resource management. Airborne and spaceborne SAR have been shown to be excellent for surface water monitoring, particularly for open water [2,3]. SAR also has considerable potential to monitor water under vegetation canopies, as long as they are not too closed for the microwave energy to penetrate and be received [4-9].

The advent of RADARSAT-2, COSMOS Sky-Med, Terra-SAR/X and the Sentinel systems, to be followed by the RADARSAT Constellation Mission (RCM), offers exciting possibilities for water resource applications through the advanced capabilities of these SAR systems. These include:

1. Interferometric data with short temporal baselines to monitor water level fluctuations and allow coherence change detection (CCD);

2. Compact polarimetric data to provide increased discrimination of water under vegetation and characterization of wetland types;

3. High resolution for monitoring smaller water bodies and wetlands; and

4. Standard modes for consistent data products in the case of Sentinel and RCM.

Recent research has demonstrated the use of repeat-pass InSAR technology to monitor water level changes in a variety of wetlands, including tropical wetlands in the Amazon, hardwood swamps in Louisiana and the mangroves and sawgrass marshes of the Everglades [10-14]. Suitable coherence has been observed at X-, C- and L-band frequencies, although the maintenance of coherence during the temporal data acquisition period is critical to this methodology. We are working to extend these techniques to wetlands in Canada. We have been able to achieve high coherence and extract phase changes that are clearly related to changes in water level [15]. However, the small size of our wetlands and the consequent problem of phase-unwrapping have hampered efforts to extract accurate water-level changes [16]. This paper reports an investigation of the information content of coherence, an interferometric indicator that is independent of phase calibration. We have found that long-term measurement of coherence provides information about the vegetation characteristics of wetlands that is additional to that provided by radar backscatter alone, and we report those findings here.

\subsection{Factors Affecting Coherence}

Coherence is a measure of the stability of the phase relationship between waves in a beam of electromagnetic (EM) radiation. Let $S_{1}$ and $S_{2}$ represent the arrays of pixels making up two carefully registered (sub-pixel precision) SAR images from the same sensor and nearly the same position. Each pixel of $S_{1}$ and $S_{2}$ is a complex number that encodes the backscattering coefficient in a particular polarization. The interferogram of the two images is given by correlating the two images:

$I=\left\langle S_{1} S_{2}^{*}\right\rangle$, and the coherence, a measure of decorrelation, is given by $[17,18]$.

$$
\gamma=\frac{\left\langle S_{1} S_{2}^{*}\right\rangle}{\sqrt{\left\langle\left|S_{1}\right|\right\rangle^{2}\left\langle\left|S_{2}\right|\right\rangle^{2}}}
$$


In this equation, the straight brackets indicate the modulus of the complex backscatter coefficients, and the angle brackets indicate an ensemble-average, that is the average over a window with a sizable number of pixels.

The phase of $\gamma$ is the measure of the difference in distance to the target between the two acquisitions, while the modulus, $|\gamma|$ indicates the stability of the phase, ranging from 1.0 when the phase is identical over the entire ensemble, to 0.0 when it is completely random.

Factors that reduce coherence include [18,19]:

- The "perpendicular baseline", which is the offset, in a direction perpendicular to the line of sight, between the two acquisitions;

- Decorrelation by:

Target motion (wind and growth);

$\bigcirc \quad$ Change in the dielectric constant, resulting in a change in the scattering phase centre;

○ Volume scattering from multiple phase centres that change from one image to the other;

$\bigcirc \quad$ Localized atmospheric phase delays (usually not important at C-band);

$\bigcirc \quad$ Misregistration of the two images (sub-pixel registration is essential);

Incorrect model of topography.

At the C-band the coherence is strongly dependent on the temporal baseline and can be maintained in herbaceous wetlands over short temporal baselines of 70 days or less [20]. In woody wetlands, the coherence at C-band may be limited by dense canopies, but tends to have a longer temporal baseline than for herbaceous wetlands. Polarization plays an important role in backscattered power and in the degree of coherence. The physics of Fresnel reflection from dielectric surfaces (water and vegetation) produces higher backscatter in $\mathrm{HH}$ polarization than $\mathrm{VV}$ polarization, resulting in generally higher coherence values obtained with RADARSAT data than ERS data [13,20]. Kim et al. [20] also found that areas dominated by woody vegetation exhibit higher coherence at C-band than areas dominated by herbaceous vegetation and maintain coherence for longer temporal baselines. Jung and Alsdorf also attribute changes in coherence to changes in vegetation type, which influences the scattering characteristics and suggests this may be due to the impact on the double-bounce scattering mechanism [21].

Conventional thinking suggests a double-bounce return may be needed to explain the coherence of wetlands at SAR frequencies with the water surface providing a surface plane and the emergent vegetation providing the vertical or near-vertical component for the double-bounce reflection. However, recent observations of coherent backscatter from wetlands in which both the coherence and the polarimetric phase are observed indicate that the backscatter that produces high coherence must include interaction with both the vegetation and the water surface, but that the double-bounce mechanism may not be as prevalent as assumed [22,23]. Indeed as pointed out by Kasischke et al. [9], multiple scattering between the vegetation and the water surface may still lead to enhanced backscatter especially for emergent herbaceous vegetation. Hong and Wdowinski [22] showed in the Everglades that the interferometric fringe pattern in cross-polarized radiation is the same as like-polarized radiation, indicating that an interaction with canopy and the water surface can become depolarized without excessive loss of coherence. Thus, it appears that although the scattering mechanism may vary in woody versus herbaceous wetlands, the underlying water surface provides a stable and uniform dielectric plane that results in coherent backscatter.

Random motion of the vegetation caused by wind and growth (enlargement) and cutting (decrease) $[19,24]$ between the two dates will decrease coherence. This factor has been shown to be more important at shorter wavelengths, because to achieve high coherence, the line-of-sight motion must be smaller than one-quarter wavelength. Woody vegetation (trees and shrubs) resist motion by wind more than herbaceous vegetation. In Canada, trees generally grow more slowly than shrubs and herbaceous plants. Changes in the dielectric constant of the vegetation or the water surface, 
particularly by freezing, can decrease coherence, as reported by Ramsay et al. [25] and observed in our early data acquisitions (Section 1.2).

\subsection{Preliminary Studies}

Research conducted by the Canada Centre for Remote Sensing (CCRS) using RADARSAT-2 data acquired in 2010 showed that numerous wetlands in a test area near Ottawa, Ontario, showed high coherence for part or all of the ice-off season [15]. Based on an analysis of the 2010 data and field visits during the 2011 winter (ice-on) season [26], the CCRS team selected 39 wetlands for monitoring during the 2011 ice-off season. They mapped their detailed vegetation characteristics, and seven were monitored for water level fluctuations during the ice-off season. In order to assess the capability of this approach for water level estimation and coherence change detection, the coherence of wetlands in the mixed forest region of Ontario near Ottawa has been measured and the results related to vegetation characteristics and relative changes in water levels. The long-term objective of this research project is to determine whether RCM C-band SAR data can be used to monitor wetlands and determine changes in water level.

The detailed objective of this study was to relate the coherence of a number of wetlands in the temperate mixed forest region of Canada throughout the ice-/snow-free season to in situ observations of vegetation characteristics, and to use the knowledge gained to propose a methodology that could lead to operational use of the data for wetland monitoring. The following sections provide more detail on the data collection and processing methodology, the results and discussion, the future work to be conducted and implications for an operational approach to water level estimation and wetland monitoring using this technology.

\section{Data and Methods}

\subsection{Test Site Description}

The test area lies mostly in the southern portion of the upper Ottawa Valley (Figure 1). The upper Ottawa Valley is defined geologically by the Ottawa-Bonnechere graben [27]. This graben was initially formed during the breakup of the supercontinent Rodinia and the formation of the Iapetus ocean about 550 million years ago, in the late Proterozoic [28]. The southwest portion of the study area lies outside of the graben, on the Canadian Shield, approximately $150 \mathrm{~m}$ higher in elevation. Outside of wetland areas, the surficial geology is predominantly glacial till from the quaternary, with small areas of glacio-fluvial and ice-contact deposits. In our study wetlands, the surficial geology has usually been classified as recent deposits of muck, peat and marl [29], with a few wetlands classified as modern alluvium composed of clay, silt, sand, gravel and muck. The parent material of the soil can play an important role in the species composition of a wetland. Of particular interest for our wetlands, the fertility of a swamp plays an important role in determining the dominant species. Black ash (Fraxinus nigra) requires high fertility; eastern white cedar (Thuja occidentalis) can occupy sites with a wide mid-range of fertility; while tamarack (Larix laricina) can thrive in areas with poor fertility [30].

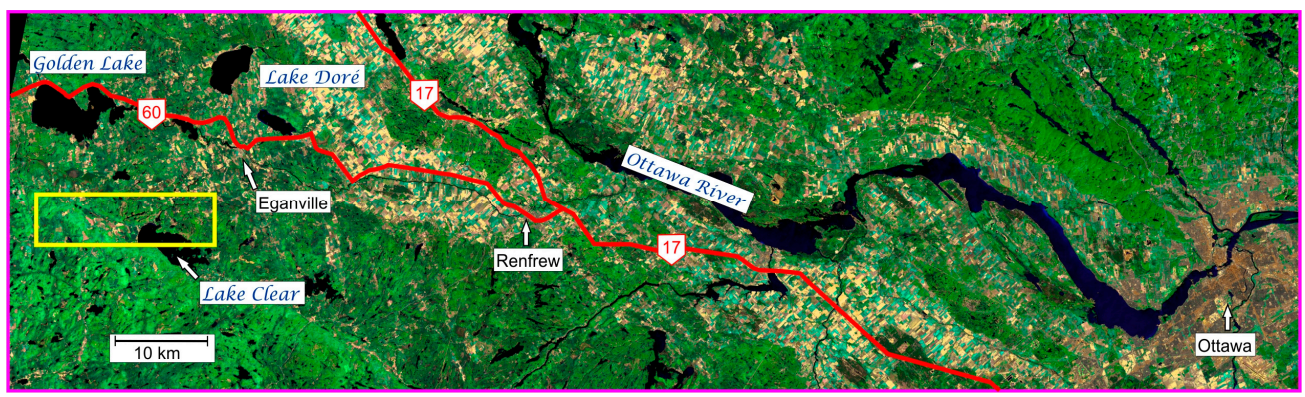

(a)

Figure 1. Cont. 


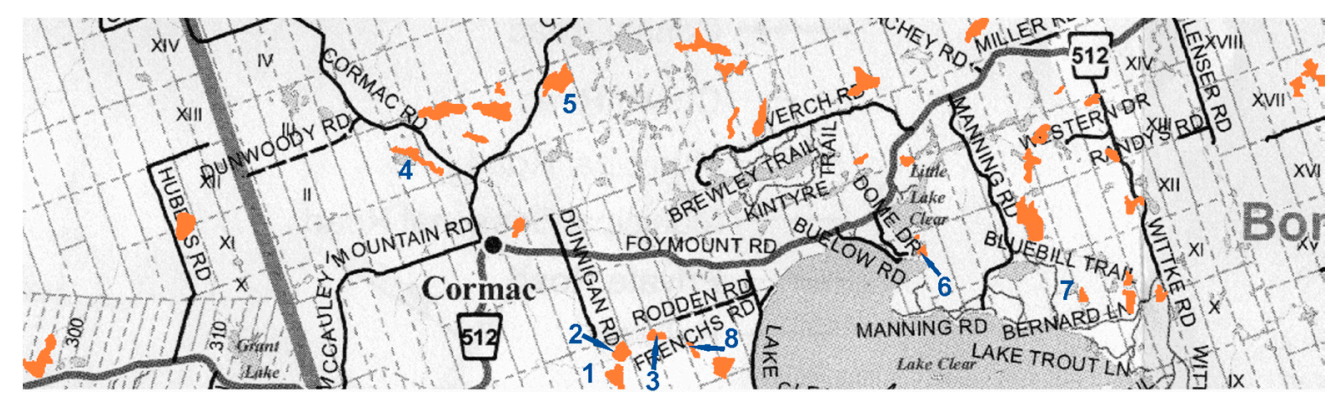

(b)

Figure 1. (a) Study area, outlined in yellow, at the southern edge of the upper Ottawa Valley, Ontario. The yellow frame marks the location of the larger-scale map. (b) Enlarged view of the study area. Study wetlands are shown in orange, with wetlands with quantitative water level monitoring numbered in blue.

\subsection{Field Data Collection}

The choice of wetlands for in situ water level monitoring and vegetation characterization was made using the following criteria:

- Relatively easy access;

- Landowner permission to install measuring stakes;

- High coherence exhibited in 2010 imagery.

The sample consisted of 39 wetlands for which the overall classification was either swamp (dominated by woody vegetation) or marsh (dominated by herbaceous vegetation) according to the Canadian Wetland Classification system [31]. However, in most cases, the wetlands were not homogeneous, so we sub-divided them according to wetland type into 60 homogeneous polygons. These consisted of 28 swamps, 25 marshes and 7 open water areas, for a total of 60 polygons. As seen, the number of swamps and marshes is nearly equal. Open water areas were expected, and subsequently observed, to have low coherence, and a smaller number of this simple cover type was deemed acceptable. Our sample wetlands are typical of a wide area of the Ottawa Valley. If there is any bias in our sample, it will be toward larger wetlands in order to provide large homogeneous areas for the radar imagery.

Seven different wetland locations for quantitative water-level monitoring were chosen using visual observations of permanently-installed tape measures. These are shown in Figure 1b:

- Lake Clear West 1, 2 and $3(1,2,3)$ : These wetlands are part of a large wetland complex composed of marsh, swamp and some open water.

- Lake Doyne Dock (4): the wetland is a mixed marsh, dominated by cattails;

- Corrigan wetland (5): This is a large area dominated with dead trees, predominantly black ash, and tall dead shrubs, predominantly alder (Alnus incana).

- Lake Clear Outlet (6): A cattail marsh that has grown on an area of sand and silt deposited at the outlet of Lake Clear.

- Lake Clear East-1 (7): This wetland is representative of four Lake Clear East wetlands that were found to have a complex shrub cover during our winter 2011 field visits. We included it because the vegetation of these wetlands is different from the vegetation of many of the other high-coherence wetlands in our 39-wetland sample. An additional wetland, Lake Clear West (4), is indicated as Number 8 in Figure $1 b$ (discussed in Section 3.2).

Evidence of dew, rain or snow on vegetation and the air temperature and the wind direction were observed and recorded. These in situ observations were supplemented with weather records obtained at the Pembroke-Petawawa airport, obtained from Environment Canada. The in situ observations were taken at approximately the same time as the satellite overpass. In addition to photographing 
our measurement stakes to enable a careful water level reading, in most cases, the wetland area in the vicinity of the measuring stakes was also photographed. These photographs provide a record of changing vegetation condition and the overall wetland environment during the course of the observing period.

\subsection{Vegetation Classification}

To provide greater understanding about the conditions under which wetlands produce high coherence, additional information about the wetlands was needed. The classification scheme used includes the following attributes: wetland type, dominant genus or species, co-dominant genus or species, vegetation structure, canopy closure of the dominant and co-dominant genus/species and health of the foliage of the dominant genus/species. Wetland type is the type of wetland following the Canadian Wetland Classification System [31]. The classes are bogs, fens, swamps, marshes and shallow open water, but there are no bogs or fens in our study area. We included this attribute as a coarse sorting criterion and to provide compatibility with other wetland studies in Canada.

Dominant and co-dominant genera or species are recorded because they constitute a primary indicator of the type of vegetation that makes up the wetland. Although there are almost always more than two species present, we found from field visits that the dominant two genera or species make up $80 \%$ or more of the crown-cover in most cases. Over-story structure classes are tree, shrub, herbaceous, bryophyte and flat. These classes have considerable redundancy with the wetland type, but the structure classes are more relevant to understanding microwave backscatter. No wetlands where bryophyte cover predominated were found. The "flat" class applies to open water and also to water covered with water lilies (Nymphaeaceae spp.) or lesser duckweed (Lemna minor).

The canopy closure of the dominant and co-dominant genus or species was recorded because this attribute is expected to play a role in microwave penetration. The classes low $(0 \%-20 \%)$, open $(21 \%-50 \%)$, closed $(51 \%-80 \%)$ and dense $(81 \%-100 \%)$ were used. These were ocular estimates from vertical the Digital Raster Acquisition Project for the East (DRAPE) imagery acquired in 2008 and oblique aerial photography obtained in October 2011.

As early as 2010, we noted that many of the wetlands with high coherence consisted of swamps with a dead or severely stressed over-story. Thus, it was important to record the canopy health of the over-story as an attribute. This attribute may also play a role in the microwave penetration and on coherence by affecting the displacement between radar image pairs caused by wind-driven motion of branches, twigs and leaves.

Digital Ontario Base Map (OBM) maps in pdf format were purchased for most of the study area and were helpful for confirming that the areas identified as wetlands from the RADARSAT-2 imagery were also classified as wetlands on the OBM. DRAPE imagery covered approximately $54,000 \mathrm{~km}^{2}$ of eastern Ontario in 2008 and 2009. The images we used for this study were obtained in May of 2008 at a time when the shade-intolerant hardwoods (primarily Populus spp.) were beginning to leaf out, but the shade-tolerant hardwoods (primarily Acer spp.) were not leafed out. Four spectral bands (blue, green, red and near IR) and one panchromatic band at higher resolution were acquired in the DRAPE project. A seamless raster database of orthorectified imagery at $20-\mathrm{cm}$ pixel spacing was produced in natural colour (red, green, blue) and made available from the Ontario Ministry of Natural Resources in the form of $1 \mathrm{~km} \times 1 \mathrm{~km}$ tiles. The geometric and radiometric quality of the data was excellent, with little evidence of seams and good use of the standard 8-bit dynamic range for each band. This was a primary data source for our wetland classification, supplemented by field visits to a large fraction of the wetlands.

Since the canopy health of the over-story was considered to be an important attribute and some of our study wetlands were not accessed on the ground, we acquired oblique digital photography from a high-wing light aircraft (Cessna 150) on 5 October 2011. The camera used was a Nikon CoolPix 5700 with 2560 pixels in the horizontal direction and 1920 in the vertical direction. This camera has a through-the-lens viewfinder and a $4 \times$ optical zoom. All images were acquired in natural colour, at the widest-angle zoom, providing a field of view of 53 degrees. It was a bright, cloudless day, allowing 
for fast exposures of $1 / 250-1 / 500 \mathrm{~s}$. The changing fall colours aided the vegetation interpretation. The oblique aerial imagery was very valuable for providing information on canopy health. In addition, the oblique view was sometimes very helpful in interpreting the canopy structure. In a few cases, marked changes in canopy health were noted between the DRAPE imagery in 2008 and the oblique imagery in 2011.

During the course of 2011, 21 of the 39 test wetlands were also visited on the ground with many digital photos obtained on each visit to help in the detailed species identification and in documenting conditions at the time of satellite overpasses.

The mapping was carried out using the Cartalinx system, a small GIS designed for data compilation rather than data analysis. It offers accurate vector processing of points, lines and polygons. Geocoded raster images can be used as a backdrop to permit heads-up digitizing. Vector editing and the addition of attribute data are easy to do. First each of the 39 wetlands was outlined as polygons. The primary data source for the wetland boundaries was an average of RADARSAT-2 spotlight mode images acquired in 2012 (see Table 1). This average image was subsequently geocoded for the delineation of boundaries. The boundaries were delineated visually using heads-up digitizing with that image as a backdrop. The backdrop was changed to the DRAPE imagery to enable the sub-division of the wetlands if there were obvious changes in wetland type within the boundary polygon. The total number of polygons after this sub-division was 60 . We then proceeded to assign the attribute data to each of the 60 polygons. The DRAPE imagery was the primary data source for the attribute data, aided by our surface and oblique aerial photography. The relevant portions of the DRAPE imagery and each oblique aerial image were contrast-enhanced for maximum interpretability of the desired information. As noted earlier, the oblique aerial photography was particularly important for assigning the class for foliar vigor. The oblique view also sometimes aided in distinguishing between the tree and shrub structure classes.

Table 1. The 2011-2013 dates of Spotlight mode acquisition. Dates with below-freezing temperatures are shown in bold. Data characteristics: polarization, $\mathrm{HH}$; range resolution, $1.6 \mathrm{~m}$; azimuth resolution, $0.8 \mathrm{~m}$; swath, $18 \mathrm{~km}$; incidence angle, $46.6^{\circ}$; frequency, $5.405 \mathrm{GHz}$ (C-band).

\begin{tabular}{lll}
\hline \multicolumn{1}{c}{$\mathbf{2 0 1 1}$} & \multicolumn{1}{c}{$\mathbf{2 0 1 2}$} & \multicolumn{1}{c}{$\mathbf{2 0 1 3}$} \\
\hline 27 February & 10 April & 23 May \\
23 March & 4 May & 16 June \\
10 May & 28 May & 10 July \\
3 June & 21 June & 3 August \\
27 June & 15 July & 27 August \\
21 July & 8 August & 20 September \\
7 September & 1 September & 14 October \\
1 October & 25 September & 7 November \\
25 October & 19 October & 1 December \\
18 November & 12 November & 25 December \\
& 6 December & \\
\hline
\end{tabular}

\subsection{RADARSAT-2 Data and Processing}

Our previous research demonstrated that C-HH Spotlight mode data were well suited for interferometry [15,32]. Table 1 shows the dates for which Spotlight mode data were acquired in 2011-2013. Spotlight mode data were acquired using beam SLA23 with an incidence angle of $46.6^{\circ}$ and a spatial resolution of $1.6 \mathrm{~m}$ in range and $0.8 \mathrm{~m}$ in azimuth. Gamma Remote Sensing and in-house tools were used to process the data. The processing can be broken into two categories: data projection and interferometry.

Data are used in two projections: radar for processing and geographic for GIS ready output products. The geometric correction of the RADARSAT-2 SAR was performed using both a digital elevation model (DEM) and an ortho-rectified optical image. Canadian Digital Elevation Data 1:50k (CDED, Natural Resources Canada, 2000) were used for the DEM. The vertical error is nominally $7.6 \mathrm{~m}$, and the posting is $0.75^{\prime \prime}$, which corresponds to $23 \mathrm{~m} \mathrm{~N}-\mathrm{S}$ by about $15 \mathrm{~m} \mathrm{E-W}$ at the study 
area. The ortho-rectified optical image is a GeoBase Orthoimage. They are generated from SPOT $4 / 5$ observations from 2005-2010, and the panchromatic band has a resolution of $10 \mathrm{~m}$.

The first step of the geocoding is to coarsely project the ortho-image to the radar coordinate system using the DEM and radar acquisition parameters. The offset of ground control points between the radar and ortho-image was used to create a transformation function to provide a precisely geocoded product. The transformation function is used to re-project the DEM to radar coordinates for topographic correction and to ortho-rectify output radar and InSAR products to geographic coordinates.

The ortho-rectified Spotlight images were compared with the polygons outlining our test wetlands (see Section 2.3). These polygons were digitized using orthorectified high resolution airborne digital optical imagery with positional accuracy of approximately $1 \mathrm{~m}$ provided by the Province of Ontario. Based on our inspection, there were residual positional errors of up to $30 \mathrm{~m}$ for the Spotlight data. The boundaries of the polygons for our test areas were moved towards the centre by $30 \mathrm{~m}$ in some cases to ensure that all of the data were extracted from areas within the wetland as shown on the RADARSAT image.

The interferometric processing of the Spotlight mode data was done with $1 \times 4$ block averaging, giving pixels with a ground pixel spacing of approximately $1.75 \mathrm{~m} \times 1.75 \mathrm{~m}$. Due to temporal de-correlation of the vegetation, processing was only done for 24-day intervals, the minimum available with RADARSAT-2. The radar products were registered using 3rd order polynomial resampling. The phases of two passes are compared to create an interferogram, which measures the phase displacement of targets between the two dates. Interferograms with topographic and baseline corrections, as well as coherence products were generated and then adaptively filtered. Due to poor coherence in forested areas between wetlands, phase unwrapping could not be performed. The coherence and differential interferogram are calculated as floating-point arrays. Each of these is converted to a 256-colour image for display purposes. Coherence has a range of values of 0.0-1.0. To make an image for display, the colour spectrum from blue to red corresponds to coherence values of $0-1$.

\section{Results}

Based on the vegetation classification scheme described above in Section 2.3, the 39 wetlands produced 60 polygons in the database. These samples were distributed among the classes as shown in Table 2. In general, the samples were well distributed across most of the classes, although there is slightly low representation of the "open" wetland type, the "shrub" and "flat" wetland structure, the "low" and "dense" canopy closure and the "stressed" health classes.

Table 2. Sample numbers for the different types of wetlands and their characteristics.

\begin{tabular}{cc}
\hline Wetland Characteristic & Number of Samples \\
\hline \multicolumn{2}{c}{ Wetland Type } \\
\hline Marsh & 25 \\
Swamp & 28 \\
Open & 7 \\
\hline Wetland Structure \\
\hline Tree & 22 \\
Shrub & 6 \\
Herbaceous & 25 \\
Flat & 7 \\
\hline \multicolumn{2}{c}{ Canopy Closure } \\
\hline Low & 7 \\
Open & 11 \\
Closed & 33 \\
Dense & 8 \\
\hline Canopy Health \\
\hline Dead & 22 \\
Healthy & 34 \\
Stressed & 4 \\
\hline
\end{tabular}




\subsection{Wetland Coherence}

In this section, we provide some analysis and discussion of the coherence we observed, stratified by several of the parameters derived from our vegetation classifications. First, we examine the correspondence between vegetation type and vegetation structure. Then, the coherence values observed with the RADARSAT-2 data are examined with respect to vegetation structure, crown closure and foliar health. Coherence is calculated by correlating the scenes in pairs separated by 24 days. The date given for the coherence is the midpoint between the two acquisitions. The error bars represent the standard error of the mean.

\subsubsection{Wetland Types and Typical Species}

In our study site sample, there were no examples of the bryophyte structural class or the bog and fen wetland types, so these were omitted from the plots and analyses. The wetland type "swamp" is sub-divided into "tree" and "shrub" structural classes in the next section. In our area, swamps are typically dominated by either conifers (eastern white cedar, Thuja occidentalis) with lesser mixtures of tamarack (Larix Laricina) or deciduous black ash (Fraxinus nigra). The shrub speckled alder (Alnus incana) is often found near the periphery and can be extensive or even dominate.

Marshes are made of mixtures of cattails (Typha spp.), grasses (Poaceae spp.) and sedges (Carex spp.), with occasional areas of bulrush (Scirpus spp.). Marshes dominated by cattails are common and can exhibit low coherence if the density is very high. There is one example of a wetland typed as "marsh", but with a "shrub" structural class. This is a small area of an unusual wetland with much human modification. The dominant vegetation was herbaceous, but there was enough shrub (alder) that "shrub" was the best structural class to assign for comparison with radar backscatter. The open water wetland type corresponds exactly to the structural class "flat". However, it is important to remember that at certain times of the year, the open water can be covered to varying extents by water lilies (Nymphaeaceae spp.) or duckweed (Lemna minor).

The coherence of the marsh and swamp shows similar annual trends with low coherence during winter and during the summer drought, but coherence values well above the 0.4 threshold for InSAR analyses during most of the ice-off and snow-free season (Figure 2).

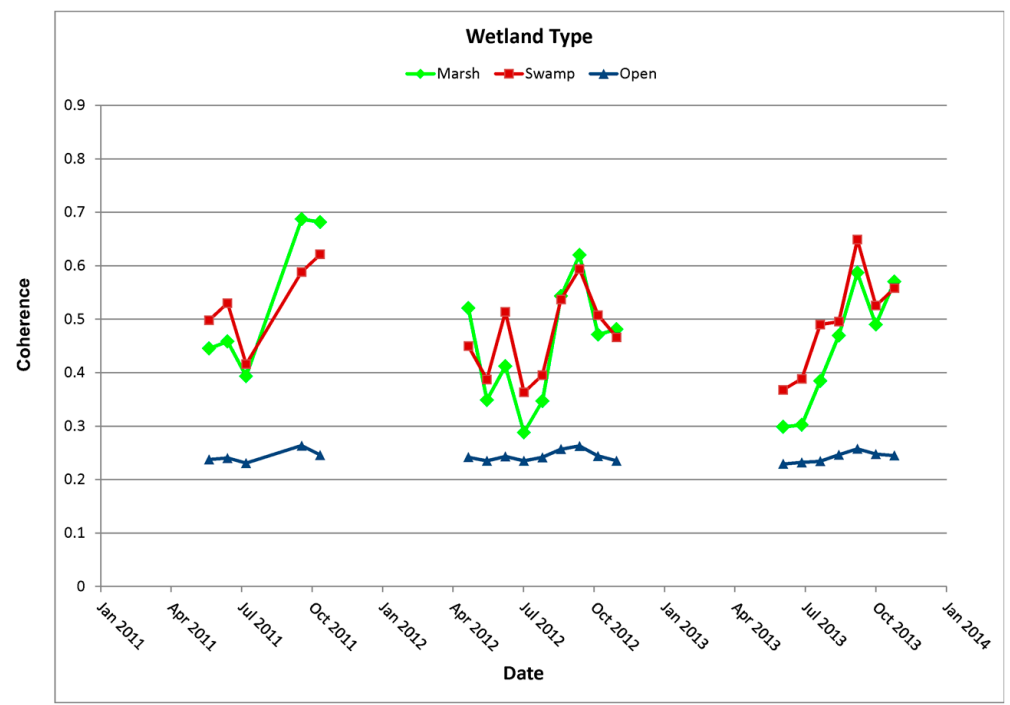

Figure 2. Coherence as a function of time for marsh, swamp and open wetland types.

\subsubsection{Wetland Structure and Canopy Closure}

Figure 3 presents a plot of coherence versus time for each structural class. The fact that the data points are separated by a greater distance than the error bars indicates that the four structural classes 
often exhibit statistically-significant differences in coherence. In particular, the "flat" class always has the lowest coherence, while the flooded vegetation classes (herbaceous, shrub and tree) have the highest coherence during the ice-off season with values mostly above 0.4 . The "tree" class exhibits the highest coherence early in the season, while the "shrub" class consistently has the highest coherence later in the growing season.

In 2011 and 2012, there was a slight dip as summer progressed, and then, the coherence increased into the fall.

The degree to which C-band microwaves penetrate a canopy is a function of the density, or crown closure, of the canopy. We next plot coherence as a function of time with crown closure as a parameter (Figure 4). The "low" and "open" crown closure classes exhibit the lowest coherence throughout the time series, while the "closed" and "dense" classes are consistently higher. This indicates that the vegetation of our wetland sample is not dense enough to greatly reduce the penetration of microwaves to the water surface.

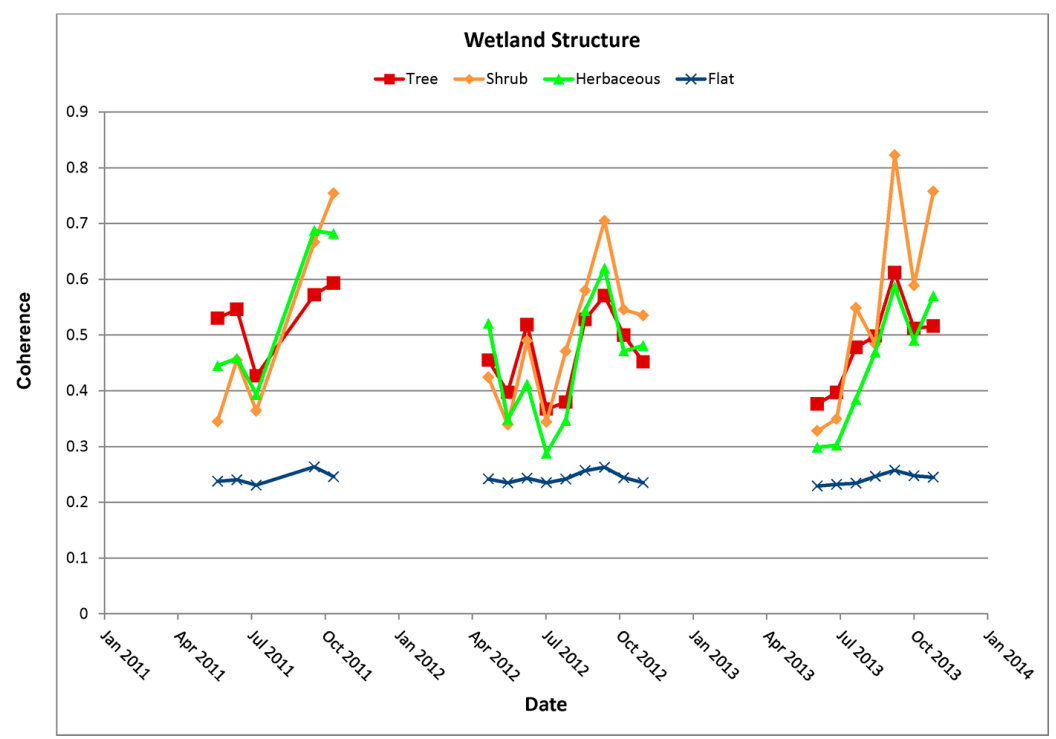

Figure 3. Coherence as a function of time for four structural classes.

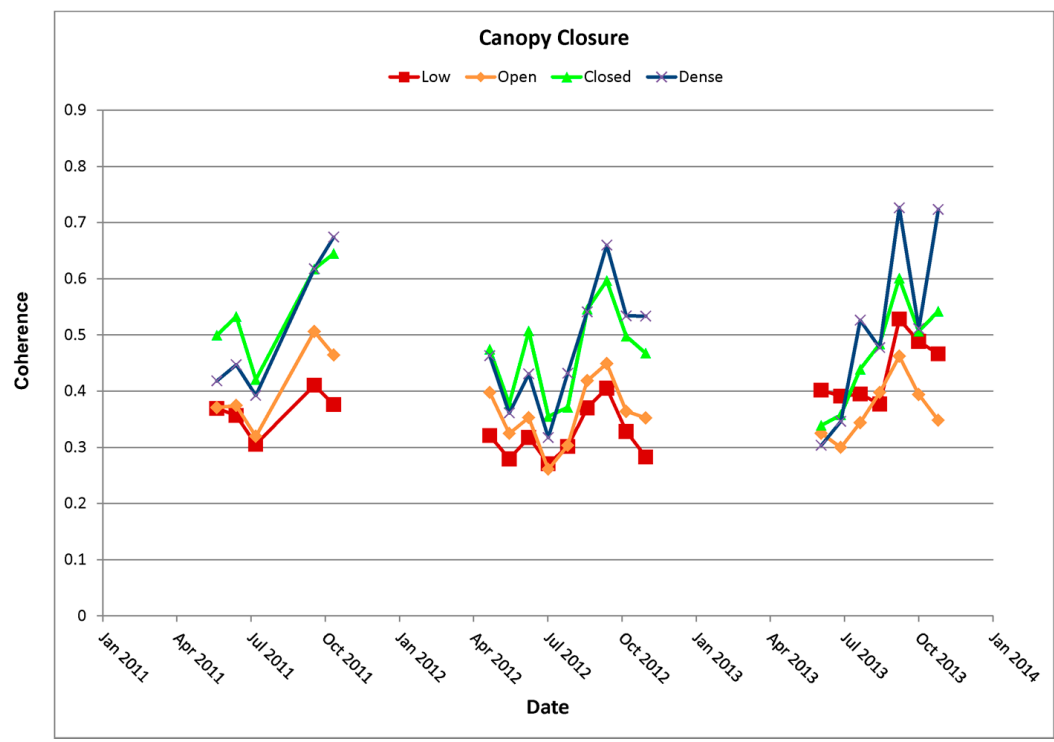

Figure 4. Coherence as a function of time for four canopy closure classes. 


\subsubsection{Wetland Canopy Health}

Figure 5 presents a plot of coherence versus time for each wetland canopy health class. The "shrub" and "herb" classes generally are "healthy", but the "tree" class is more often "dead" or "stressed". This is not a statement about all of the wetlands in our study area, but rather the sample that we selected for detailed study. The primary criterion used to identify our study wetlands was high C-band radar coherence throughout the ice-off season. While we did specifically add nine wetlands that exhibited low coherence, an additional 30 wetlands had high coherence. The high-coherence selection criterion may be selecting against healthy tree canopies because the $\mathrm{C}$-band radiation is attenuated too much by the canopy or because a canopy with healthy foliage may move more in the wind, thus reducing coherence. While the "dead" class consistently exhibited the highest coherence and the "stressed" class consistently exhibited the lowest coherence, the "healthy" class varied more widely, from as low as the "stressed" class to as high as the "dead" class. This is difficult to explain with the data available because of the number of complicating factors that we have mentioned: canopy penetration, wind-induced motion and the fact that our sample combines "tree", "shrub" and "herbaceous" structural classes.

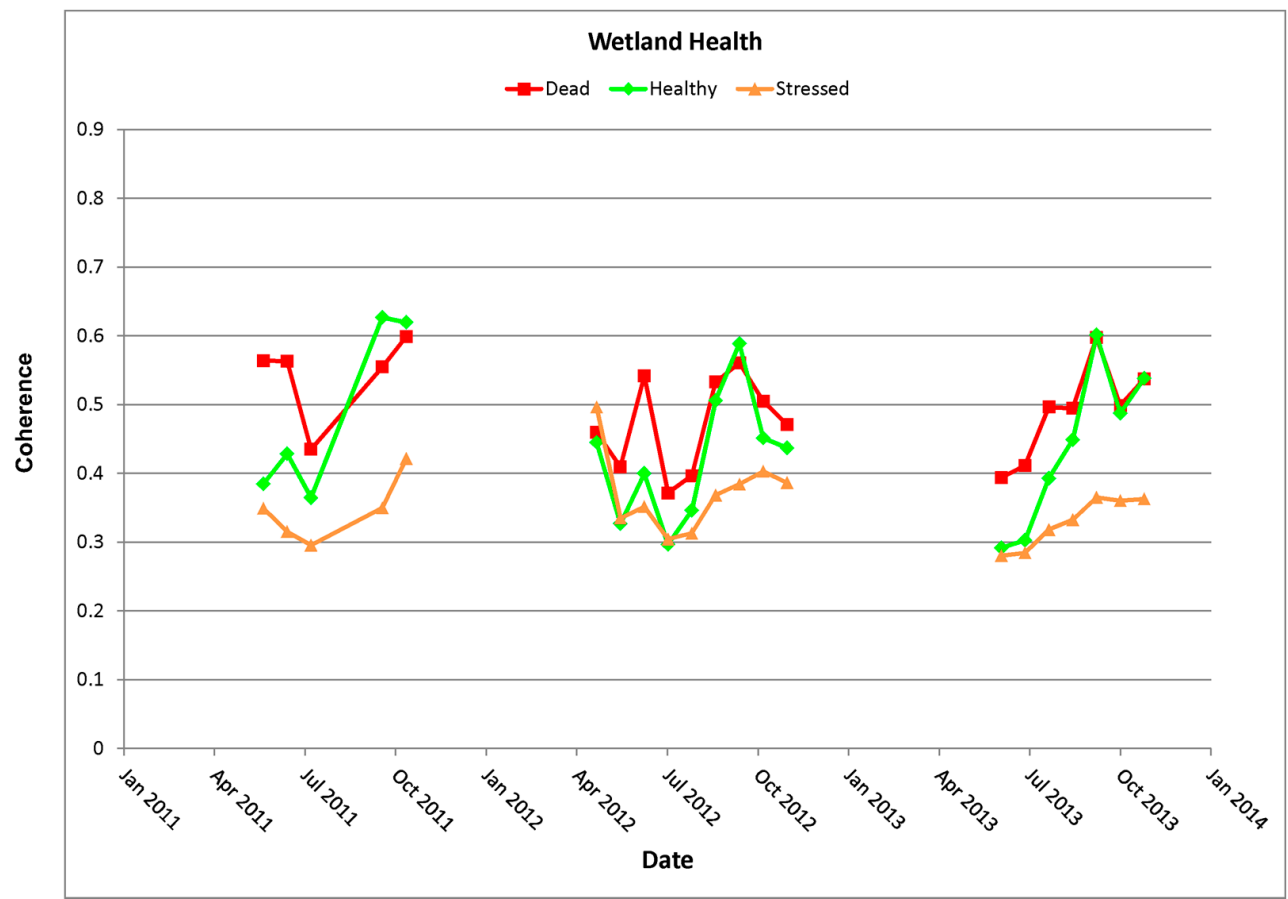

Figure 5. Coherence as a function of time for three canopy health classes.

\subsubsection{Seasonal Changes and Baseline Effects}

In addition to the relationships between coherence and wetland characteristics, we note some pronounced seasonal changes that can be seen in Figures 2-5. The coherence is near 0.3 for the first interferometric pair in 2011, in which both images were acquired at below-freezing temperatures. During the winter, the freeze/thaw events, new snowfall and wind effects cause snow to be non-coherent at the C-band as both the dielectrics and the internal geometry of the snow and ice are constantly changing. In the spring of 2011, the coherence rises rapidly, falls in July and, then, rises into the fall. We see a double dip in the earlier part of the growing season of 2012. There was a prolonged drought in 2012, which ended in August, followed by normal precipitation for the remainder of the growing season. Our initial interpretation of these changes was to relate them to changing water level. However, when we correlated the coherence with water level for the sample of seven wetlands for which we monitored changes in water level, there was no strong relationship between water level and 
coherence for these particular wetlands. These seasonal fluctuations in the coherence pattern require further investigation.

We have investigated the effects of the perpendicular baseline on coherence. No relationship between perpendicular baseline and coherence was found. This is not surprising: all of the perpendicular baselines were under $300 \mathrm{~m}$, which is a much shorter distance than the 22-km critical baseline or the 7-km practical baseline for the Spotlight mode of RADARSAT-2.

Note that only the open wetland type (equals flat structural type) has consistently too low a coherence value for water level estimation. In general, most swamp and marsh wetlands have suitable coherence for water level estimation for much of the growing season. Also noteworthy are the variations in average coherence between wetlands at any given time and in a wetland over time. This suggests that coherence change detection has some merit for wetland monitoring, which is described in more detail in the next section.

\subsection{Coherence Change Detection for Wetland Monitoring}

During the observation period in 2010 and 2011, two of the wetlands we were monitoring experienced significant water level fluctuations due to drainage changes. These changes are shown in Figure 6. In the first case, a wetland that had low coherence in 2010 and much of 2011 due to low water levels suddenly had high coherence late in the season. Upon field visitation, we found that the wetland was now flooded due to beaver activity, which had built a dam across the outlet creek causing a significant water level increase. During the same time period, a wetland that had quite high coherence early in 2010 suddenly had a drop to low coherence. Once again, a field visit determined that the drainage outlet had been plugged, causing high water levels and significant flooded vegetation, but had subsequently been cleared by the landowner, resulting in lower water levels and a loss of coherence.

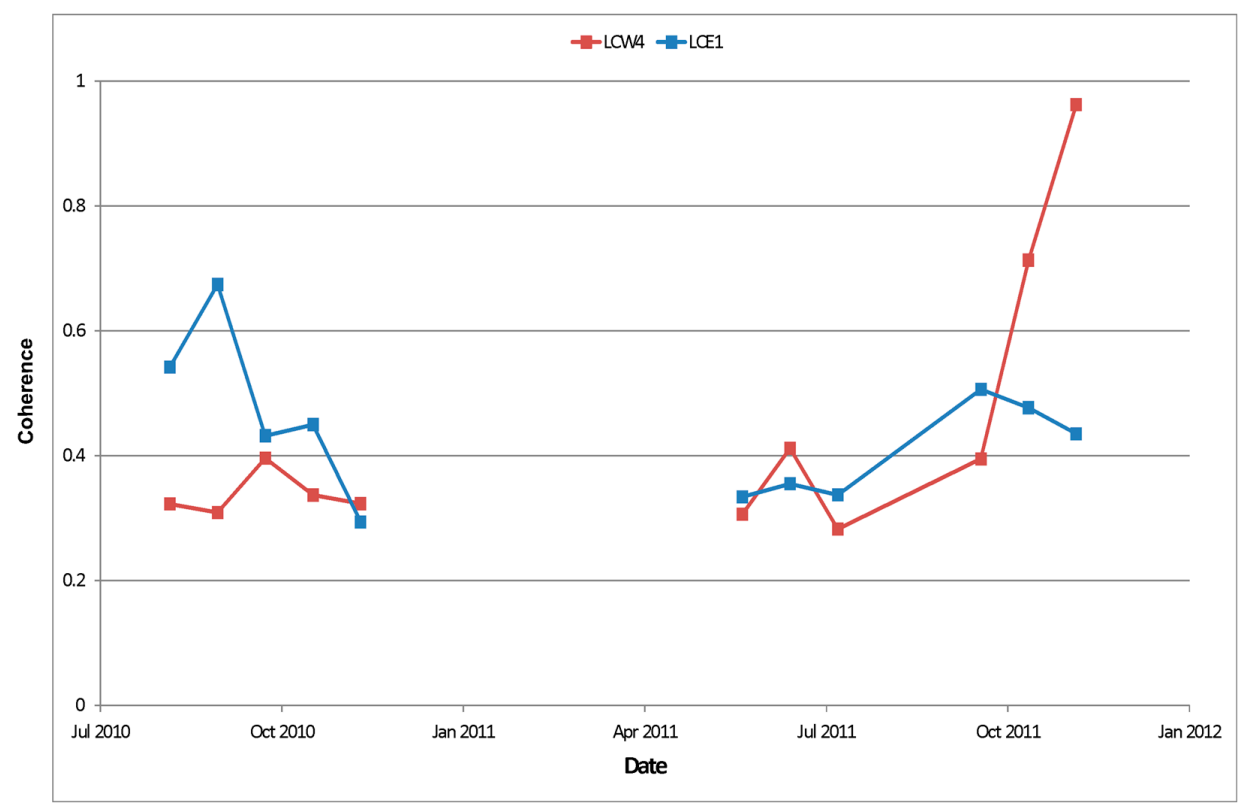

Figure 6. Wetlands Lake Clear West- 4 and Lake Clear East-1 coherence profile for 2010/2011 showing abrupt changes in coherence due to sudden changes in water level.

These observations suggest that coherence change detection (CCD) can be an effective tool for monitoring drainage status and water level in wetlands. The wetland locations could be identified from a wetland inventory, such as the Canadian Inventory, a GIS database of key wetland locations, such as the Ramsar Convention, key National and Provincial parks or any other geo-referenced information source, such that a simple CCD could be used to monitor flood status. 


\subsection{Temporal Coherence for Wetland Characterization}

Most of the wetlands show temporal changes within a year that vary with wetland type, wetland structure, canopy closure and health (Figures 2-5). In this section, the annual temporal variation of 60 wetland polygons over the three-year ice-off period was examined. The graphs (Figure 7a,b) show the annual average and the standard deviation of 180 points. As shown in the graphs, the changes could be interpreted using the mean and standard deviation of annual coherence.

Freshwater marshes are flooded for most of the year. Winter brings seasonal rains and snows that raise water levels for the remainder of the year. They are characterized by herbaceous plants that grow in the summer and senesce during the winter. With the emergent herbaceous vegetation, double-bounce scattering between the vegetation and the water surface enhances coherent backscatter, which increases the coherence over the growing season (Figure 3). Freshwater marshes can dry out in hot weather and dry spells, leaving smaller pools of water and lower coherence. Changes of herbaceous vegetation phenology and marshland water level influence the coherence of marshes. As shown in Figure 7a, the standard deviation (annual change of coherence) of marshes (herbaceous class in Figure $7 \mathrm{~b}$ ) increases with the coherence, and the relationship is almost linear. Here, the annual change of coherence is mostly caused by herbaceous vegetation growth.

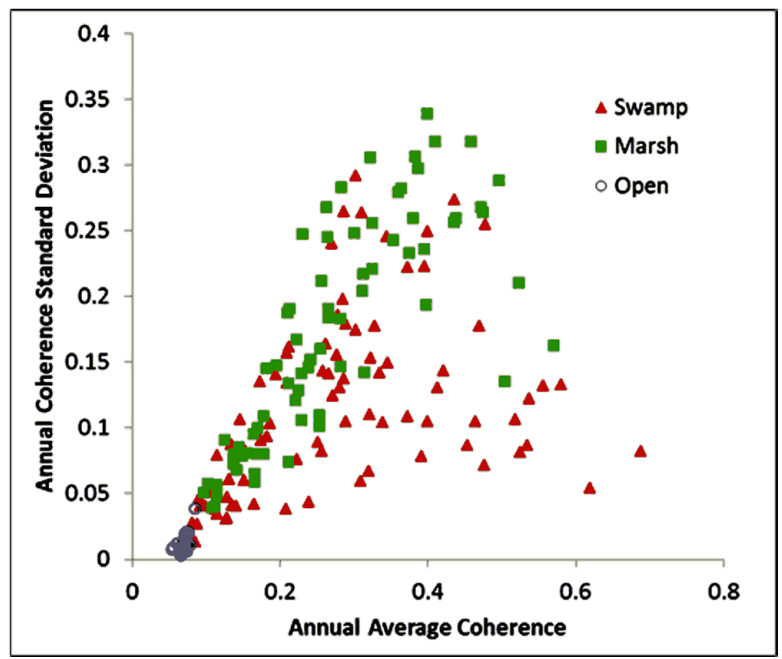

(a)

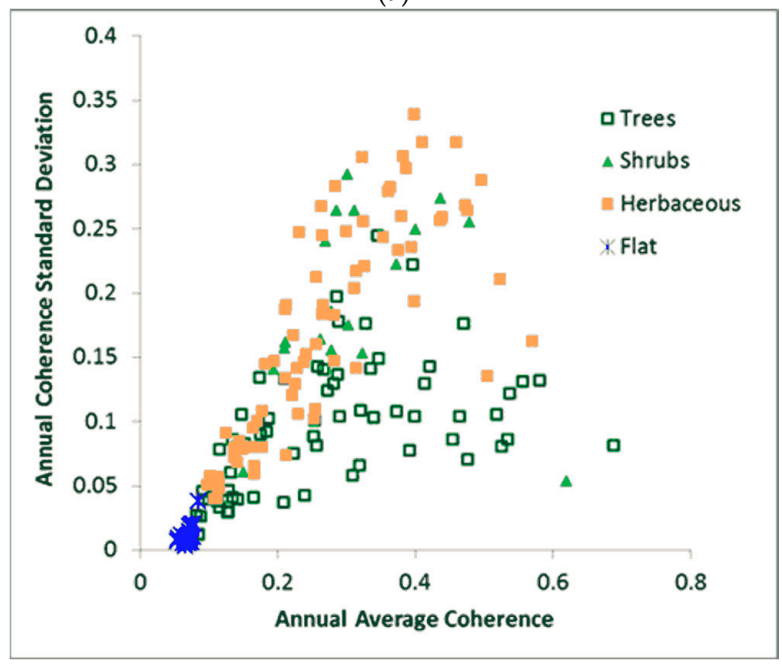

(b)

Figure 7. Annual average coherence and standard deviation of 60 wetlands over three-year ice-off period (total of 180 points): (a) sorted by wetland type; (b) sorted by wetland structure. 
Swamps are wetlands that have trees and shrubs. In the swamps that consistently exhibit high coherence, the trees are mostly dead. Double-bounce return from dead trees clearly explains the coherence of treed wetlands (Figure 7). The coherence increases with the vertical or near-vertical component above the water surface that provides double-bounce reflection. As the trees are dead, the annual coherence is generally stable; therefore, the standard deviation is relatively low. Swamps with shrubs also yielded high coherence at the C-band due to double-bounce scattering. However, the coherence change of shrub swamp is affected by the growth of branches and the growth and senescence of leaves (Figure 3), resulting in a standard deviation that is similar to herbaceous wetlands (Figure $7 \mathrm{~b}$ ). Both the coherence and the standard deviation for open (flat structural class) wetlands are low, creating a compact cluster in the lower left corner of Figure 7a,b.

A new image coherence product for the ice-off temporal stack of data was developed to effectively visualize the coherence data. Examples for the three-year time period for Lake Clear are shown in Figure 8 . This false colour image was created by:

1. Assigning mean coherence for all ice-free datasets in a year to the red channel;

2. Assigning the standard deviation of coherence for these data to the green channel;

3. Assigning the standard deviation of intensity of these data to the blue channel and;

4. Calculating an IHS transform with mean intensity as the backdrop.

These image coherence products (Figure 8) are useful for visualizing the coherence data and for highlighting wetlands. The tree-dominated swamp wetlands have medium to high coherence with a low variance and high intensity, such that they appear reddish on the false color image, while increasing proportions of shrubs changes the colour to orange and yellow as the standard deviation of the coherence increases. Marsh wetlands are predominately yellow because they have high coherence and a high standard deviation. The Lake Clear temporal coherence products are consistent from year to year because of similar wetland and water level characteristics. The water is dark because of its low mean intensity. Upland deciduous forests are blue-gray, while coniferous forests are green, indicating a higher variability in coherence. The wetlands are both bright and coherent and thus show up quite clearly as pink, red and yellowish colours. This highlights the value of the image coherence products for monitoring flooded vegetation and identifying general land cover, including wetlands.

These image coherence products have three fundamental advantages over the single-channel SAR images they were derived from:

1. Coherence provides different information than intensity [25,33]. Although there is some correlation between intensity and coherence, in wetlands, important deviations are observed when coherence is plotted against intensity [20]. Therefore, a product like ours that combines both coherence and intensity will provide more information than either data source alone;

2. Speckle in the two images used to produce an interferogram is highly correlated, so speckle in the coherence image is less than speckle in the individual images [19];

3. The mean intensity that is used to modulate the colours also has less speckle than individual images because of temporal averaging.

Figure 9 was produced by displaying all wetland polygons' mean and standard deviation with the approximate colours they have on the coherence products shown in Figure 8. As shown in Figure 8, these image coherence products can be useful for change detection and wetland monitoring, which can highlight seasonal change, especially in the marshes, as well as give some indication as to vegetation density and structure as the different wetland types behave differently.

Based on Figure 7 and its description, the three sides of the wetland coherence triangle (Figure 9) represent an increasing or decreasing level of seasonal change (mainly seasonal vegetation growth), vegetation density (density of vertical components) and vegetation structure (stable vegetation). The triangle is easy to use for characterizing wetlands once it is understood. The herbaceous vegetation 
is identified on the left side of the triangle with orange, yellow and green colors. From the lower left corner (open water) to the top of the triangle (healthy herbaceous vegetation), the seasonal vegetation growth increases; therefore, the annual coherence standard deviation increases. The bottom of the triangle identifies the density of vegetation vertical components. From the lower left corner to the lower right corner, the coherence increases from $\sim 0-0.7$, corresponding to an increase of vegetation vertical components. Further, the change in vegetation structure is identified along the right side of the triangle. From the top of the triangle to the lower right, the vegetation structure changes from herbaceous to shrubs and to trees. Based on these three properties, one can identify the wetland characteristics from the colour of the image coherence products.

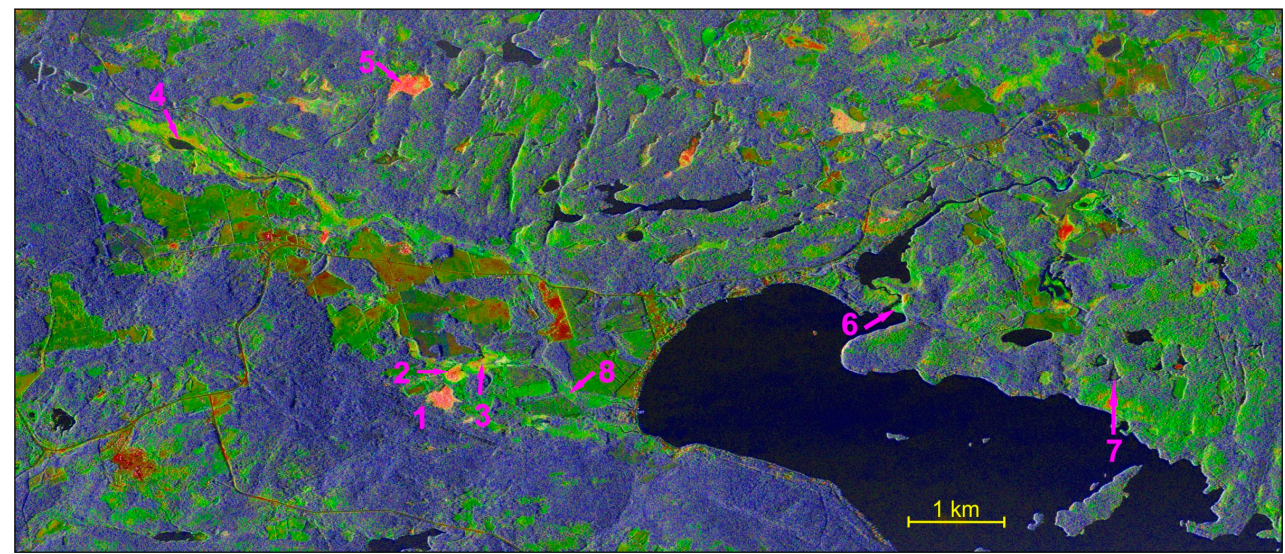

(a) 2011

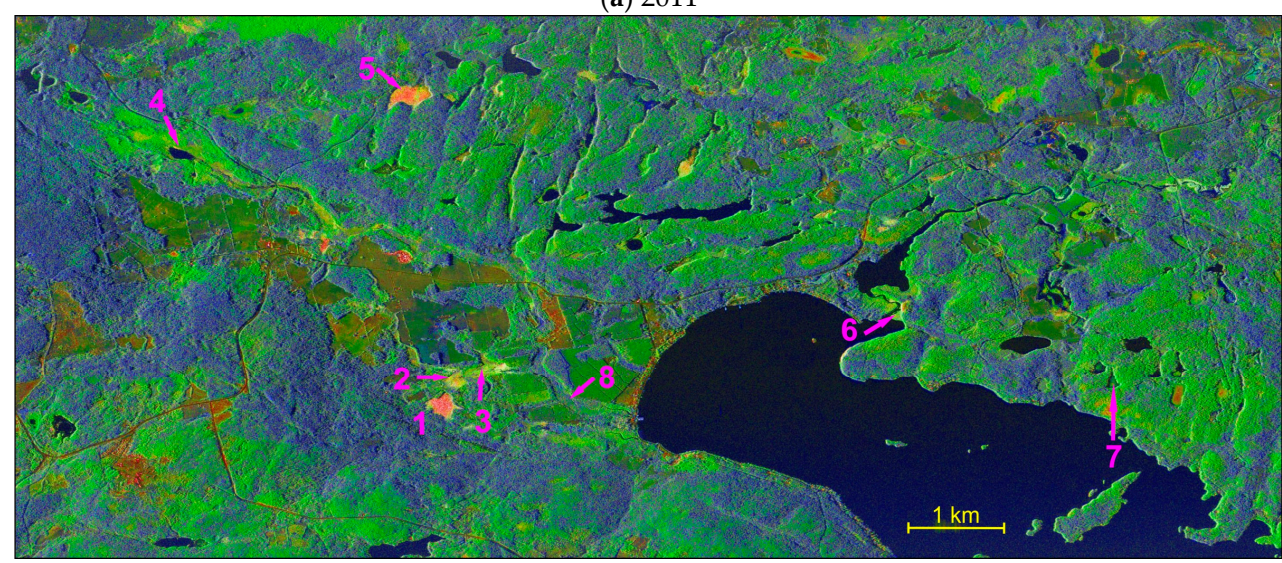

(b) 2012

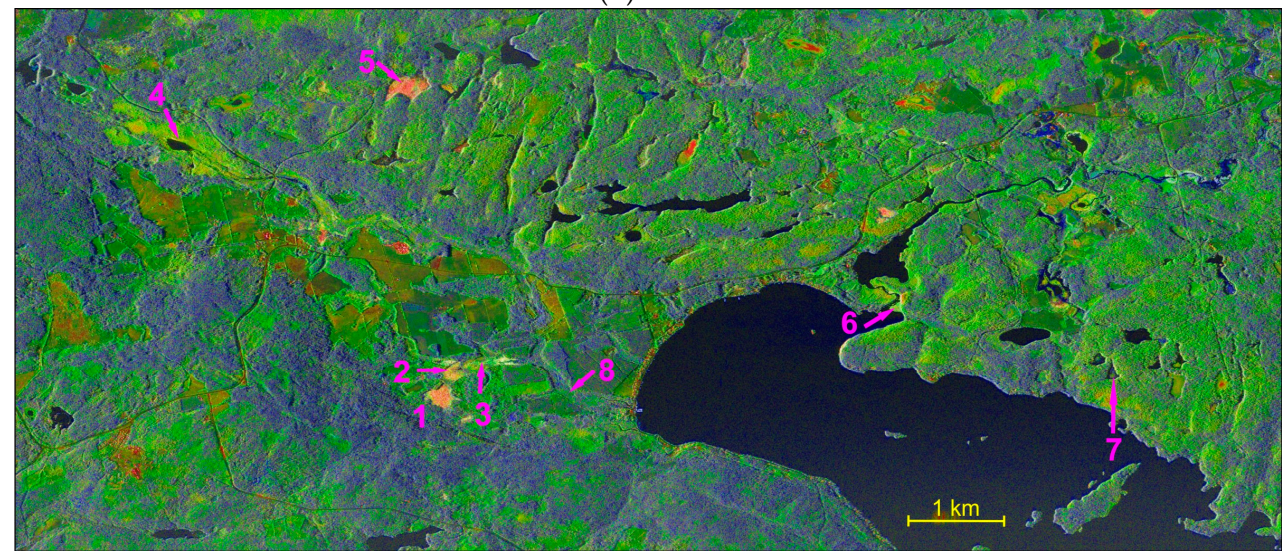

(c) 2013

Figure 8. Example of image coherence products for the Lake Clear test site: (a) 2011 data; (b) 2012 data; (c) 2013 data. Wetlands of note are numbered as indicated in Section 2.2. 


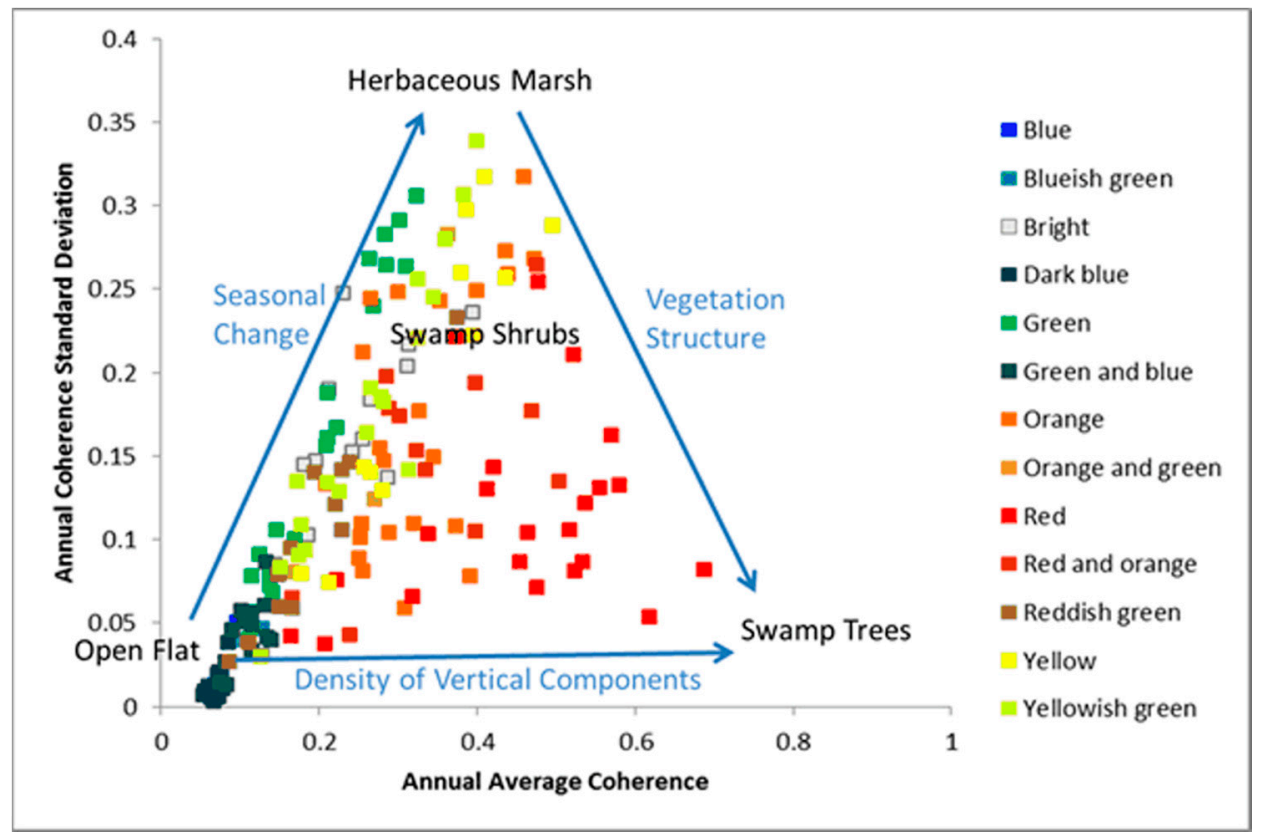

Figure 9. Standard deviation of annual coherence versus average annual coherence of the wetland polygons in the Lake Clear study site.

\section{Discussion and Relevance}

Monitoring extensive areas of small wetlands represents a formidable task for water resource managers in many parts of Canada. In Ontario, for example, the provincial government continues to place increasing restrictions on development in areas in and around wetlands, but has limited capabilities for monitoring. Remote sensing capabilities that would permit monitoring of both long-term and abrupt changes of individual wetlands and their interconnections across entire watersheds will be most welcome. In this study, we have:

- Determined that coherence remains high throughout the ice-free season for the majority of wetlands;

- Discovered relationships between changes in coherence and vegetation type;

- Developed a novel colour image product that can be used to identify and classify wetlands and watch for changes over wide areas;

- Developed an accompanying interpretation key to enable managers to use the product without knowledge of the intricacies of SAR and interferometry.

This knowledge and these new application tools represent an important advance in the application of SAR imaging for wetland management.

The production and interpretation of these colour composites constitute a robust approach that can be readily adopted by water resource managers worldwide. Given the increasing availability and greatly decreasing cost of radar imagery and the associated software, we encourage researchers and managers involved in wetland ecology to try this novel approach.

\section{Conclusions}

The ability to monitor many small wetlands with high resolution over extensive areas would provide a valuable additional tool for water management. Our analysis of a sample of 39 wetlands in the mixed forest temperate region of North America demonstrates that this is feasible using InSAR time series. 
Our interferometric analysis shows that high coherence can be obtained from many well-distributed small wetlands in the Bonnechere Valley, a sub-watershed of the Ottawa River. This area is typical of much of southern Canada east of the prairies. The majority of these wetlands are swamps, with tree or shrub cover, and marshes, with herbaceous cover. Coherence is acceptably high in the spring, summer and fall, but not in winter.

This paper provides findings that are consistent with previous research in other countries, while extending them to small Canadian wetlands. We have found that inundated vegetation shows high coherence during the ice-off time period, with the greatest stability exhibited by swamps with dead trees. The greatest variability in coherence is shown by marshes, where there is major growth and change of the herbaceous vegetation during each growing season. Swamps with extensive shrub cover typically show high coherence, but variability that is intermediate between that of marshes and treed swamps.

Coherence change detection offers promise as a monitoring tool for drawing attention to sudden wetland changes. The coherence can drop rapidly when a wetland is drained or increase rapidly when a new area becomes flooded. This change can be flagged for follow-up investigation to determine the cause and remedy if appropriate.

We have developed a readily-interpretable colour image product that highlights wetlands and that can be used for a preliminary discrimination of swamps, marshes and open water associated with emergent vegetation. This product combines measures of image coherence and its variability, with radar backscatter, producing information content that is greater than either source alone. We have developed a clustering diagram that aids in the interpretation of the image product in terms of vegetation type and dynamics.

With the existing SAR satellites, such as Terra-SAR/X and COSMO SkyMed, Sentinel and the upcoming RADARSAT Constellation Mission, which will all provide frequent revisits, there will be ample data available to apply effective CCD techniques, such as those described here, for mapping and monitoring wetlands. Data stacks are becoming the standard with SAR applications and will facilitate this technique.

Acknowledgments: This research project was supported by the Remore Sensing Science program at Earth Science Sector/Canada Centre for Remote Ssensing and the Canadian Space Agency through the Radarsat Constellation Mission-Coherence Change Detection funding. Thanks to Sergey Samsonov, Shimon Wdowinski and four anonymous reviewers from Remote Sensing for making valuable comments that helped improve this manuscript. Earth Science Sector Contribution Number/Numéro de contribution du Secteur des sciences de la Terre: 20130057.

Author Contributions: Brian Brisco conceived of and designed the experiment and guided its implementation and execution. Kevin Murnaghan and Lori White planned the RADARSAT data acquisition and carried out RADARSAT data processing. Frank Ahern planned the field campaign, which was carried out with the assistance of Philip Lancaster and Kevin Murnaghan. He also carried out the delineation and characterization of the sample wetlands and polygons. Kevin Murnaghan developed the colour composite image product, and Francis Canisius developed the interpretation key. All of the authors contributed to the data interpretation and preparation and revision of this paper.

Conflicts of Interest: The authors declare no conflict of interest. The founding sponsors had no role in the design of the study; in the collection, analyses or interpretation of data, in the writing of the manuscript; nor in the decision to publish the results.

\section{References}

1. IPCC (Intergovernmental Panel on Climate Change). Climate Change and Water; IPCC: New York City, NY, USA, 2008.

2. Brisco, B. Water resource applications with RADARSAT-2-A preview. Int. J. Digit. Earth 2008, 1, 130-147. [CrossRef]

3. Brisco, B.; Short, N.; van der Sanden, J.; Landry, R.; Raymond, D. A semi-automated tool for surface water mapping with RADARSAT-1. Can. J. Remote Sens. 2009, 35, 336-344. [CrossRef] 
4. MacDonald, H.C.; Waite, W.P.; Demarcke, J.S. Use of Seasat satellite radar imagery for the detection of standing water beneath forest vegetation. In Proceedings of the Rainbow 80; Fall Technical Meeting, Niagara Falls, NY, USA, 7-10 October 1980.

5. Hess, L.L.; Melack, J.; Simonett, D. Radar detection of flooding beneath the forest canopy: A review. Int. J. Remote Sens. 1990, 11, 1313-1325. [CrossRef]

6. Kasischke, E.S.; Bourgeau-Chavez, L.L. Monitoring South Florida wetlands using ERS-1 SAR imagery. Photogram. Eng. Remote Sens. 1997, 63, 281-291.

7. Pope, K.O.; Rejmankova, E.; Paris, J.F.; Woodruff, R. Detecting seasonal flooding cycles in marshes of the Yucatan Peninsula with SIR-C polarimetric radar imagery. Remote Sens. Environ. 1997, 59, 157-166. [CrossRef]

8. Townsend, P.A. Relationship between forest structure and the detection of flood inundation in forested wetlands using C-band SAR. Remote Sens. Environ. 2002, 23, 443-460. [CrossRef]

9. Kasischke, E.S.; Smith, K.B.; Bourgeau-Chavez, L.L.; Romanowicz, E.A.; Brunzell, S.M.; Richardson, C.J. Effects of seasonal hydrologic patterns in south Florida wetlands on radar backscatter measured from ERS-2 SAR imagery. Remote Sens. Environ. 2003, 88, 423-441. [CrossRef]

10. Alsdorf, D.; Smith, L.; Melack, J. Amazon floodplain water level changes measured with interferometric SIR-C radar. IEEE Trans. Geosci. Remote Sens. 2001, 39, 423-431. [CrossRef]

11. Lu, Z.; Kwoun, O.I. Radarsat-1 and ERS InSAR analysis over southeastern coastal Louisiana: Implications for mapping water-level changes beneath swamp forests. IEEE Trans. Geosci. Remote Sens. 2008, 46, 2167-2184. [CrossRef]

12. Wdowinski, S.; Kim, S.W. Space based detection of wetlands' surface water level changes from L band SAR interferometry. Remote Sens. Environ. 2008, 112, 681-696. [CrossRef]

13. Kim, S.W.; Lu; Lee, H.; Shum, C.K.; Swarzenski, C.M.; Doyle, T.W.; Baek, S.H. Integrated analysis of PALSAR/Radarsat-1 InSAR and ENVISAT altimeter data for mapping of absolute water level changes in Louisiana wetlands. Remote Sens. Environ. 2009, 113, 2356-2365. [CrossRef]

14. Hong, S.-H.; Wdowinski, S.; Kim, S.W.; Won, J.S. Multi-temporal monitoring of wetland water levels in the Florida Everglades using Interferometric Synthetic Aperture Radar (INSAR). Remote Sens. Environ. 2010, 114, 2436-2447. [CrossRef]

15. Brisco, B.; Ahern, F.J.; Murnaghan, K. InSAR for Monitoring Water Level Changes in Canadian Wetlands; Canadian Space Agency Info Days: St. Hubert, QB, Canada, 2011.

16. Murnaghan, K.; Brisco, B.; Ahern, F.J.; Lancaster, P.; Wdowinski, S. Ambiguity resolution using radar reflectors for InSAR monitoring of water level. In Proceedings of the Canadian Space Agency Advanced SAR Conference, St. Hubert, QB, Canada, 15-18 October 2013.

17. Prati; Rocca, F. Improving resolution of stationary objects with multiple SAR surveys. IEEE Trans. Aerosp. Electron. Syst. 1993, 29, 135-144. [CrossRef]

18. Olesk, A.; Antropov, O.; Zalite, K.; Arumäe, T.; Voormansik, K. Interferometric SAR coherence models for characterization of hemiboreal forests using TanDEM-X Data. Remote Sens. 2016, 8, 1-23. [CrossRef]

19. Hagberg, J.O.; Ulander, L.M.; Askne, J. Repeat-pass SAR interferometry over forested terrain. IEEE Trans. Geosci. Remote Sens. 1995, 33, 331-340. [CrossRef]

20. Kim, S.W.; Wdowinski, S.; Amelung, A.; Dixon, T.H.; Won, J.S. Interferometric coherence analysis of the everglades wetlands, South Florida. IEEE Trans. Geosci. Remote Sens. 2013, 51, 1-15. [CrossRef]

21. Jung, H.C.; Alsdorf, D. Repeat-pass multi-temporal interferometric SAR coherence variations with Amazon floodplain and lake habitats. Int. J. Remote Sens. 2010, 31, 881-901. [CrossRef]

22. Hong, S.-H.; Wdowinski, S. Double bounce component in cross-polarimtric SAR from a new scattering target decomposition. IEEE Trans. Geosci. Remote Sens. 2013, 52, 3039-3051. [CrossRef]

23. Brisco, B.; Ahern, F.J.; Hong, S.-H.; Wdowinski, S.; Murnaghan, K.; White, L. Polarimetric decompositions of temperate wetlands at C-Band. IEEE J. Sel. Top. Appl. Earth Obs. Remote Sens. 2015, 8, 3585-3594. [CrossRef]

24. Wegmuller, U.; Werner, C. Retrieval of vegetation parameters with SAR interferometry. IEEE Trans. Geosci. Remote Sens. 1997, 35, 18-24. [CrossRef]

25. Ramsey, E.; Rangoonwala, A.; Rykhus, R. Multiple baseline radar interferometry applied to coastal land cover classification and change analyses. GISci. Remote Sens. 2006, 43, 283-309. [CrossRef]

26. Ahern, F.J. An Assessment of Candidate Wetlands for Coherent Detection of Water Level Changes with RADARSAT-2 Data; Canada Centre for Remote Sensing: Ottawa, ON, Canada, 2011. 
27. Eyles, N. Ontario Rocks: Three Billion Years of Environmental Change; Fitzhenry and Whiteside: Markham, ON, Canada, 2002.

28. Carr, S.D.; Easton, R.M.; Jamieson, R.A.; Culshow, N.G. Geologic transect across the Grenville orogeny of Ontario and New York. Can. J. Earth Sci. 2000, 37, 193-216. [CrossRef]

29. Barnett, P.J.; Ainsworth, B. Quaternary Geology of the Brudenell Area, Southern Ontario; Ontario Ministry of Northern Development and Mines: Sudbury, ON, Canada, 1982.

30. Chambers, B.A.; Naylor, B.J.; Niepola, J.; Merchant, B.; Uhlig, P. Field Guide to Forest Ecosystems of Central Ontario; Ontario Ministry of Natural Resources: Peterborough, ON, Canada, 1997.

31. Wells, E.D.; Zoltai, S. The Canadian system of wetland classification and its application to circumboreal wetlands. Aquilo Ser. Bot. 1985, 21, 45-52.

32. Brisco, B.; Murnaghan, K.; Wdowinski, S.; Hong, S.-H. Evaluation of RADARSAT-2 acquisition modes for wetland monitoring applications. Can. J. Remote Sens. 2015, 41, 431-439. [CrossRef]

33. Kim, J.W.; Lu, Z.; Jones, J.; Shum, C.K.; Lee, H.; Jia, Y. Monitoring Everglades freshwater marsh water level using L-band synthetic aperture radar backscatter. Remote Sens. Environ. 2014, 150, 66-81. [CrossRef]

(c) 2017 by the authors; licensee MDPI, Basel, Switzerland. This article is an open access article distributed under the terms and conditions of the Creative Commons Attribution (CC BY) license (http:/ / creativecommons.org/licenses/by/4.0/). 